Journal of Japan Association for Earthquake Engineering, Vol. 12, No. 6 (Special Issue), 2012

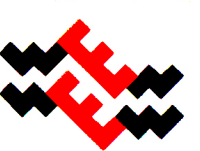

\title{
DETECTION OF BUILDING DAMAGE IN THE 2010 HAITI EARTHQUAKE USING HIGH-RESOLUTION SAR INTENSITY IMAGES
}

\author{
Pralhad UPRETY ${ }^{1}$ and Fumio YAMAZAKI ${ }^{2}$ \\ ${ }^{1}$ PhD Student, Department of Urban environment System, Chiba University, \\ Chiba, Japan, pralhaduprety@yahoo.com \\ ${ }^{2}$ Professor, Department of Urban environment System, Chiba University, \\ Chiba, Japan, yamazaki@tu.chiba-u.ac.jp
}

\begin{abstract}
Two sets of high-resolution SAR imageries from TerraSAR-X were used to calculate radar characteristics like correlation coefficient and backscatter difference for building damage detection after the 2010 Haiti earthquake in the city center of Port-au-Prince. The Normalized Difference Vegetation Index from a Quickbird image was used to delineate non-vegetated areas. The threshold values for correlation coefficient and backscatter differences were determined to find the change. By our threshold values, we could achieve reasonable detection accuracy in low- and moderate-density areas.
\end{abstract}

Key Words: The 2010 Haiti Earthquake, SAR intensity image, Building damage detection, TerraSAR-X

\section{INTRODUCTION}

Time factor is an important part in disaster situation and in such situation remote sensing can be a great boon. Remote sensing is the science of acquiring, processing and interpreting images that record the interaction between the electromagnetic energy and materials (Sabins 1996). With the advancement of technology, satellite remote sensing has become a great tool in disaster studies and found wider application including building damage detection (Huyck et al. 2002, Saito and Spence 2004, Yamazaki et al. 2005).

Depending upon the sensor type, satellite system can be broadly divided into active and passive systems. Passive sensors as in optical satellite systems (e.g., Ikonos, QuickBird, GeoEye, WorldView-1,2) usually depend on the solar energy for image recording whereas in active sensors as in a radar satellite system energy is emitted by itself and thus it is being used at both daytime and nighttime. Beside that a radar system like synthetic aperture radar (SAR) can penetrate clouds giving its advantage over an optical satellite in recording the surface condition in needy hours. This is the reason why SAR has been utilized in the disaster situations including earthquakes, floods and so on (Matsuoka and Yamazaki 2004, 2005, 2010; Stramondo et al. 2006, Rathje and Adams 2008, Thao et al. 2010).

Radar satellite systems operate in different bands like L-band (frequency, $f: 1-2 \mathrm{GHz}$ and wavelength, $\lambda: 15-30 \mathrm{~cm}), \mathrm{C}$-band $(f: 4-8 \mathrm{GHz}$ and $\lambda: 3-7.5 \mathrm{~cm}), X$-band $(f: 8-12 \mathrm{GHz}$ and $\lambda: 15-30$ $\mathrm{cm})$ and so on. The common choice of the radar band depends upon the application desired. Some currently available SAR satellite systems are PALSAR, TerraSAR-X, Radarsat, and ERS. PALSAR 
(L-band, $f: 1.27 \mathrm{GHz}, \lambda: 23.6 \mathrm{~cm}$ ) from JAXA captures the images in three modes with resolution of $7-88 \mathrm{~m}$ at varying angle of incidence $\left(8-60^{\circ}\right)$. ERS-1 (C band, $f: 5.3 \mathrm{GHz}, \lambda: 5.5 \mathrm{~cm}$ ) from European Space Agency produces images in $30 \mathrm{~m}$ resolution, VV polarization at an angle of 23 degree. Radarsat-1 (C band, $f: 5.40 \mathrm{GHz} \lambda: 5.5 \mathrm{~cm}$ ) from Canadian Space Agency is $\mathrm{HH}$ polarization system and captures images in 8-100 $\mathrm{m}$ resolution at varying angle of incidence $\left(10-60^{\circ}\right)$. Radarsat-2 is also C-band but has different polarization combination as well as high-resolution (up to $3 \mathrm{~m}$ ) acquisition capacity. TerraSAR-X (X band, $f: 9.65 \mathrm{GHz}, \lambda: 3.11 \mathrm{~cm}$ ), a satellite from German Space Agency (DLR) can acquire wide spectrum of data with different polarization combinations. The resolution of image varies 1.1 to $18 \mathrm{~m}$ taken at incidence angle of 20-55 . COSMO-SkyMed from Italian Space Agency is an X-band system and has capacity to produce the image of ground resolution of $1-100 \mathrm{~m}$. High resolution images (1-3 m) from COSMO-SkyMed are available only in single polarization mode.

Depending upon the satellite system employed, backscatter characteristics varies. This is because the backscatter characteristics are different for the different wavelength, angle of incidence and orientation of objects because of the surface roughness, permittivity and permeability (Lillesand and Kiefer 2000, Matsuoka and Nojima 2010). Likewise, the azimuth resolution is higher for shorter wavelengths while penetration power is more in larger wavelengths. Similarly, same feature can appear different for different wavelengths. As surface roughness is defined in terms of the radar wavelength, same surface which appear smooth may appear rough at a longer or sorter wavelength. When the object like a building is along the direction of SAR illumination, it will be seen bright in the SAR image due to the corner reflection.

$\mathrm{X}$-band is highly sensitive to small changes and hence can be employed in the urban change detection. With the advent of high-resolution SAR imagery (on the order of a decimeter) from TerraSAR-X and COSMO-SkyMed, it has become possible to measure the precise change and has found wide application in different fields like agriculture, urban land-use and so on. Many features in urban areas can be identified which is important in the aftermath of a disaster like a devastating earthquake. Many researches have carried out disaster monitoring and building damage detection using SAR images. However, the researches on building damage detection are on a block level, not in an individual building level. In this paper, we try to extract damaged buildings at an individual level in Port-au-Prince, the capital of Haiti, using pre- and post-event high-resolution TerraSAR-X intensity images.

\section{THE 2010 HAITI EARTHQUAKE AND DATA EMPLOYED}

Haiti is the poorest developing country in the western hemisphere. Its capital is Port-au-Prince, which is located on the south of country on the bay of Port-au-Prince. The capital was established in 1749 $\mathrm{AD}$, where about $30 \%$ of Haitian population live and is the powerhouse of the country as more than $90 \%$ of investment and the formal jobs are found here (Republic of Haiti 2003). The population of Port-au-Prince was just 9,400 in 1789 and after 1950 it increased in such a way that estimated population in the year 2008 was 2.7 million (UN-HABITAT, 2009). Regarding the housing type distribution in Port-au-Prince, Kayate (combined roof and walls) comprises $0.3 \%$, Taudis/Ajoupas (housing made mainly of waste construction materials including stone/wood) $2.5 \%$, ordinary one-story house $62.5 \%$, ordinary multi-story house/apartment $30.3 \%$ and others comprise $4.2 \%$, respectively. Kayate and Taudis/Ajoupas are houses made by the poor. Similarly, the dominant wall types of Haitian houses are follows: earth (74.1\%) in Kayate, earth (42.6\%) in Taudis/Ajoupas, concrete/blocks/stone $(75.7 \%)$ in ordinary single-story house, concrete $(96.8 \%)$ in ordinary multi-story house/apartment house, and concrete $(48.2 \%)$ in other housing types (Institute Haitien de Statistique d'information 2010 cited by Eberhand et al. 2010). Ground observation by Cambridge Architectural Research (2010) reported that most of the houses were $1-2$ stories and vast majority $(65-75 \%)$ is reinforced concrete (RC) type.

Though the country has been frequently affected by natural disasters like hurricane, landslide and flood, major earthquakes had not occurred for a long time. Past notable earthquakes include those of 1701, 1751, 1770 and 1860 (USGS 2010). After about 150 years of time gap, an earthquake of moment magnitude 7.0 hit Haiti on January 12, 2010 at 4:53 PM local time, affecting many parts of the country including cities like Leogane, Jacmel, Petit-Goave and Port-au-Prince. The epicentre was 
located at Leogane (Lat. $18.44^{\circ} \mathrm{N}$, Long. $72.57^{\circ} \mathrm{W}$ ), about $17 \mathrm{~km}$ from Port-au-Prince. The depth of earthquake was $13 \mathrm{~km}$. This earthquake severely affected Haiti: 217, 000 people died, more than 300,000 people were injured (Eberhard et al. 2010) and about 3 million people were affected out of which 2.1 million people have been displaced (UNDP 2010).

Many important structures including Presidential Palace, National Cathedral, and Headquarter of United Nations Stabilization in Haiti (MINUSTAH) were severely damaged. In a total of 403,176 buildings were damaged (UNDP 2010). Besides building damage, liquefaction (Olson et al. 2011) and local tsunami (USGS 2010) were also reported due to this earthquake. Economic loss from this disaster is estimated as USD 7.9 billion, which is just over 120 percent of the country's gross domestic product in 2009 (Government of Haiti 2010). High casualty and property losses made this event the most deadly one in the history of Haiti. This event was the most destructive event in any country when compared with the death of people to the total population of a nation in modern times (Cavollo et al. 2010).

The data employed in this research are from the German TerraSAR-X satellite system, which works at X-band (wavelength of $3.11 \mathrm{~cm}$ and frequency of $9.65 \mathrm{GHz}$ ). TerraSAR-X is the world's first earth observation SAR satellite with X-band sensor onboard and has a repeat cycle of 11 days. A pre-event SAR image was acquired on September 17, 2008 (15 months before) and a post-event image was obtained on January 14, 2010 ( 2 days after). The acquisition mode of the images was StripMap with $\mathrm{HH}$ polarization and an incidence angle of 39.32 degrees. The satellite path was ascending with right-looking. These images have a ground resolution of $3 \mathrm{~m}$ and pixel spacing of $1.25 \mathrm{~m}$. The employed data were Enhanced Ellipsoid Corrected (EEC) product with map geometry, projected into WGS84 reference ellipsoid. Fig. 1 shows the location and the pre-and post-event SAR images used in this study. Out of the whole images, a target area for the study was extracted as shown in Fig. 2.

Optical images were also used for assessing the results from the TerraSAR-X images. A pre-event image was from QuickBird (February 4, 2009) while post-event images were from GeoEye (January 13, 2010) and WorldView-2 (January 15, 2010).

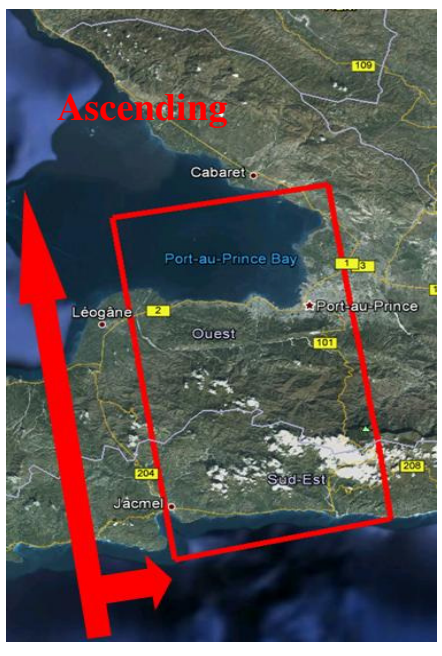

(a) SAR data coverage area

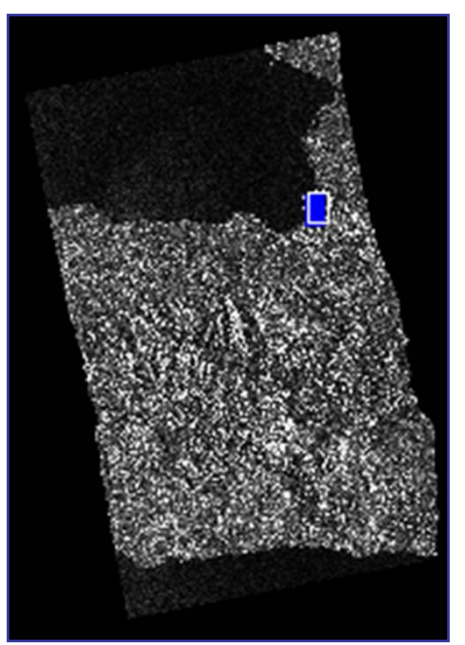

(b) Before (Sep. 17, 2008)

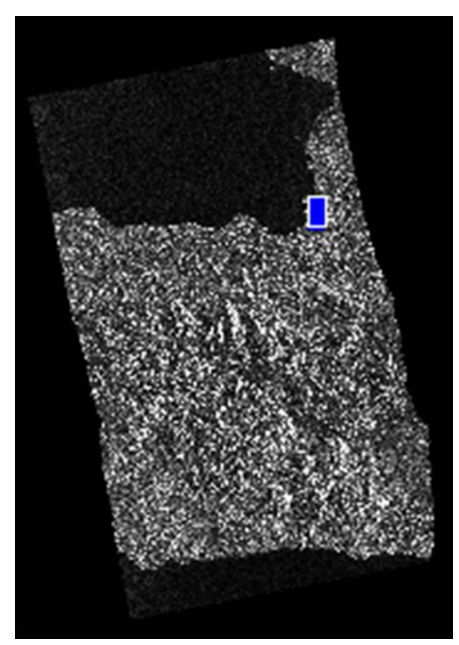

(c) After (Jan. 14, 2010)

Fig. 1 SAR data used in this study and their coverage. Red rectangle in (a) shows the geographic area covered by TerraSAR-X in Google Earth. Blue rectangles in (b) and (c) show the study area. 


\section{DAMAGE DETECTION METHODOLOGY}

Firstly, the study area was selected in the capital city, Port-au-Prince, covering downtown, the most visible damage like the presidential palace, and the areas both common in optical and radar images. Then an accurate positioning of two SAR intensity images was carried out. The next step was re-sampling of the intensity images to alter the spatial resolution from $1.25 \mathrm{~m}$ to $0.6 \mathrm{~m}$ so as to make comparison with the pan-sharpened optical images. Lee adaptive filter (Lee 1980) of $21 \times 21$ pixel window was applied to each SAR image to remove speckle noises. Since the radar image is in the slant range, it has to be converted into the ground range to represent the true feature and this is done by radiometric calibration. Radiometric calibration of each intensity image was carried out to get the backscattering coefficient in the ground range (sigma naught, $\sigma^{0}$ ) from equation (1) (Infoterra 2008, Breit et al. 2010). Radar characteristics, viz the backscattering difference value $(d)$ and the correlation coefficient $(r)$, were calculated within a different pixel window size of the pre- and the post-event images using equations (2) and (3). Finally a $21 \times 21$ pixel window size to obtain $d$ and $r$ was determined in this study.

$$
\sigma \circ=10 \log _{10}\left(C F * D N^{2}\right)+10 \log _{10}\left(\sin \theta_{l o c}\right)
$$

where $\sigma^{0}$ means the backscatter per unit area in the ground range, $\mathrm{CF}$ is the calibration factor, DN is the digital number of a pixel and $\theta_{l o c}$ is the incidence angle, which can be found in the Geo-coded incidence angle mask file.

$$
\begin{gathered}
d=\bar{I} a_{i}-\bar{I} b \\
r=\frac{N \sum_{i=1}^{N} I a_{i} I b_{i}-\sum_{i=1}^{N} I a_{i} \sum_{i=1}^{N} I b_{i}}{\sqrt{\left(N \sum_{i=1}^{N} I a_{i}{ }^{2}-\left(\sum_{i=1}^{N} I a_{i}\right)^{2}\right) \cdot\left(N \sum_{i=1}^{N} I b_{i}{ }^{2}-\left(\sum_{i=1}^{N} I b_{i}\right)^{2}\right)}}
\end{gathered}
$$

where $I a_{i}, I b_{i}$ represent the $i$-th pixel values (backscattering coefficients) of the post-event and pre-event images, respectively and $\bar{I} a_{i}, \bar{I} b_{i}$ are the average values of the $21 \times 21$ pixels surrounding the $i$-th pixel. The correlation coefficient $(r)$ is a scalar quantity and its value ranges between -1.0 and 1.0 and is used to find the measure of correspondence between two-sample populations (Brown 1992).

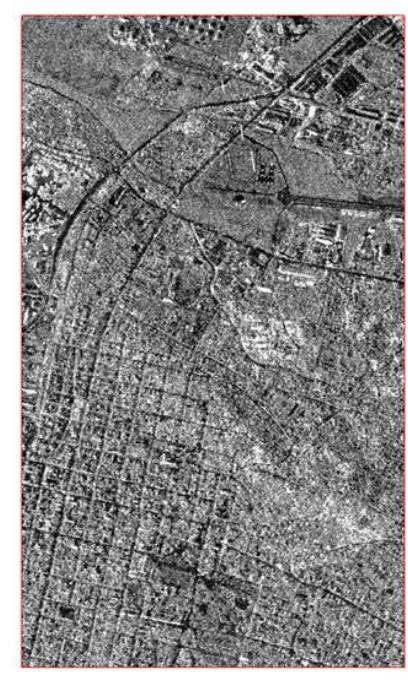

Before (Sep. 17, 2008)

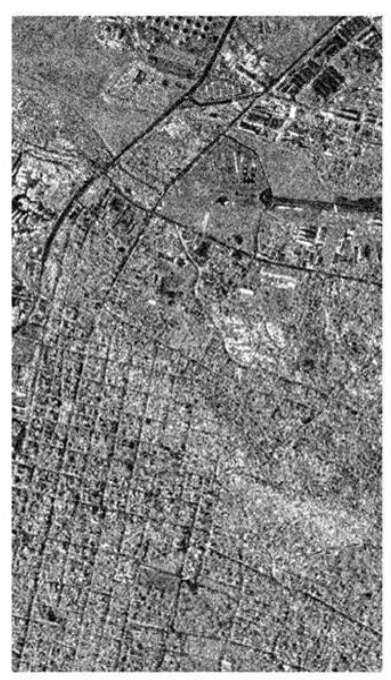

After (Jan. 14, 2010)

Fig. 2 Radiometrically calibrated images of the study area.

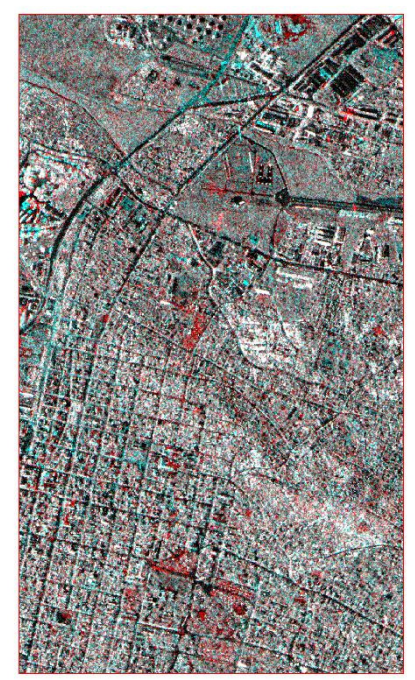

Color composite (R: post-event scene, cyan: pre-event scene) 


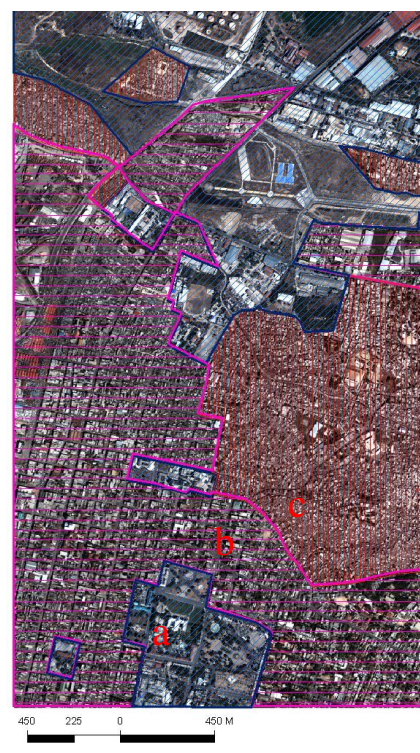

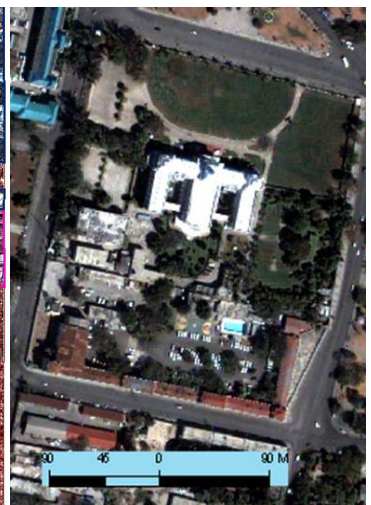

(a) Low

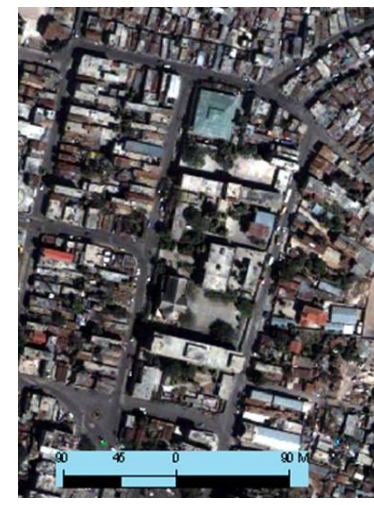

(b) Moderate

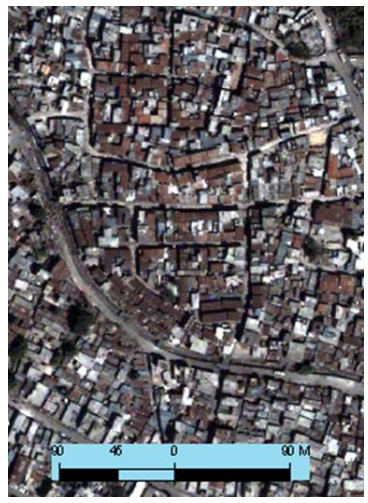

(c) High

Low

Moderate

$\mathrm{High}$

Fig. 3 Classification of study area based on urban density. An example of each class is given for (a) low-density, (b) moderate-density, and (c) high-density areas.

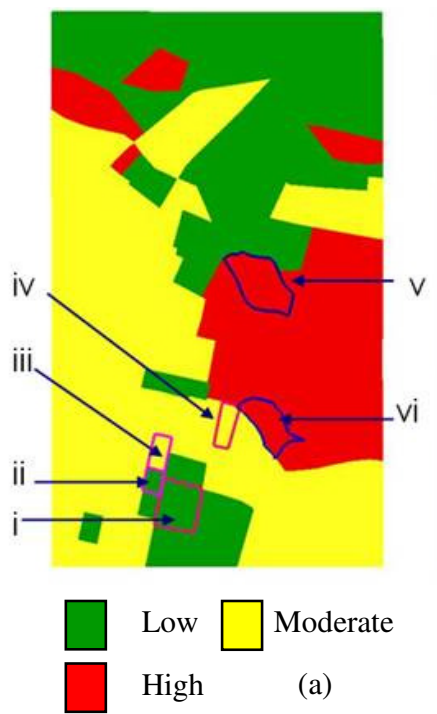

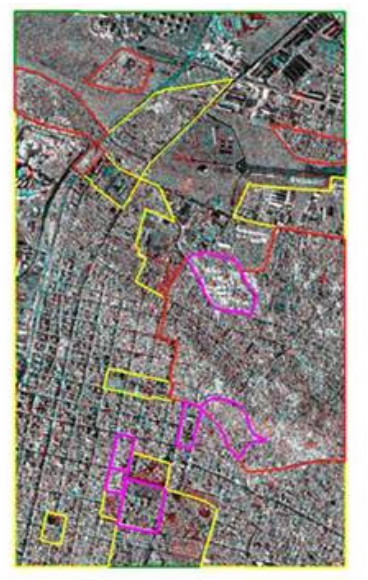

(b)

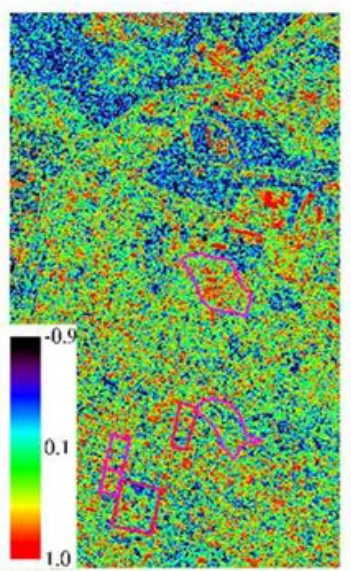

(c)

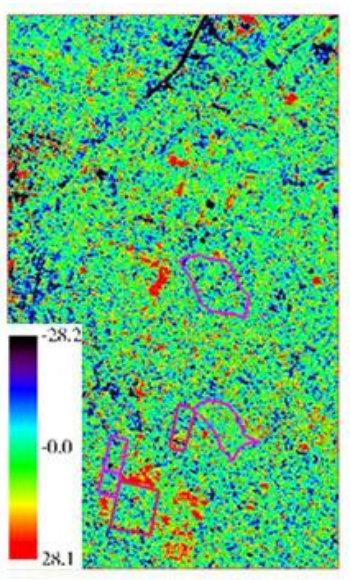

(d)

Fig. 4 (a) Urban density of the study area. The sampled areas in each density class are marked from (i) to (iv), (b) color composite (Red: post-event scene, Cyan:

pre-event scene), (c) correlation coefficient, (d) difference of backscatter coefficients.

Next the study area was divided into low-, moderate-, and high-building density areas from visual observation using the pre-event optical satellite image Fig. 3 shows the classification of the study area based on urban density and an example of each class. It is to be noted that the division into different density areas could not be done quantitatively due to the lack of the GIS data of building polygon in the study area. But regarding the sample areas in low- and moderate-density, there were 55 buildings per $78,131 \mathrm{~m}^{2}$ and 109 buildings per $46,925 \mathrm{~m}^{2}$, respectively.

Fig. 4 shows the result of urban classification and the corresponding color composite, correlation and backscattering coefficient maps. Fig. 4(a) shows the urban density and the sampled areas of each density class while Fig. 4(b) is the color composite of calibrated SAR images (red: post-event scene, cyan: pre-event scene). Red areas mark the possible changes aftermath of an earthquake; cyan (Blue + Green) areas represent decreased backscatter while grey areas show the unchanged areas over the time. Likewise, Fig. 4(c) and Fig. 4(d) are the correlation coefficient and the difference of the backscattering 
coefficients (after-before), respectively. In the study area, the correlation coefficient value ranges from -0.9 to 1.0 while the backscattering coefficient difference ranges from -28.1 to $28.2 \mathrm{~dB}$.

Man made structures including buildings in an urban area produce strong backscatter to the radar. It can be seen more easily in a high resolution SAR image as TerraSAR-X. Due to side-looking nature of SAR, buildings facing to the SAR illumination look bright. In an urban area, double scattering (corner reflection) from the ground to a building wall facing the SAR illumination is also common. As radar collects information in the slant-range domain, a radar image inherently contains geometric errors like layover, radar foreshortening and shadowing (Campbell 2002). In an urban area, layover is common as the response from the top of a building comes earlier to the satellite than that from its base. Fig. 5 shows a schematic diagram of SAR interaction with a building.

Considering these backgrounds, we extend the size of building polygons facing the SAR illumination in a GIS environment. This is because; previously building polygons were drawn on the basis of the vertical optical image while the SAR illumination is side-looking. To illustrate this idea, we took one sample area as seen in Fig. 6. Footprints of buildings facing the SAR illumination were extended equal to the layover length of the average height of buildings under consideration. The layover length $L=H /(\tan \theta)$ was estimated assuming the average height of buildings as $10 \mathrm{~m}$ and using the SAR incidence angle $\theta=39.32$ degrees. The heights of buildings were calculated from the optical images using the elevation and azimuth of the satellite and the sun as well as the length of shadow cast by buildings (Huang and Kwoh 2007, Iwasaki and Yamazaki 2011).

There are altogether 29 building polygons out of which 2 were G-5, 4 were G-4, 1 was G-3 and rest 22 were G1-2. When we overlay different threshold values of the Normalized Difference Vegetation Index (NDVI), the effect of vegetation particularly trees was seen in the extended part of damaged buildings. So, rather than using extended footprint we use the building footprint only in this case of Port-au-Prince.
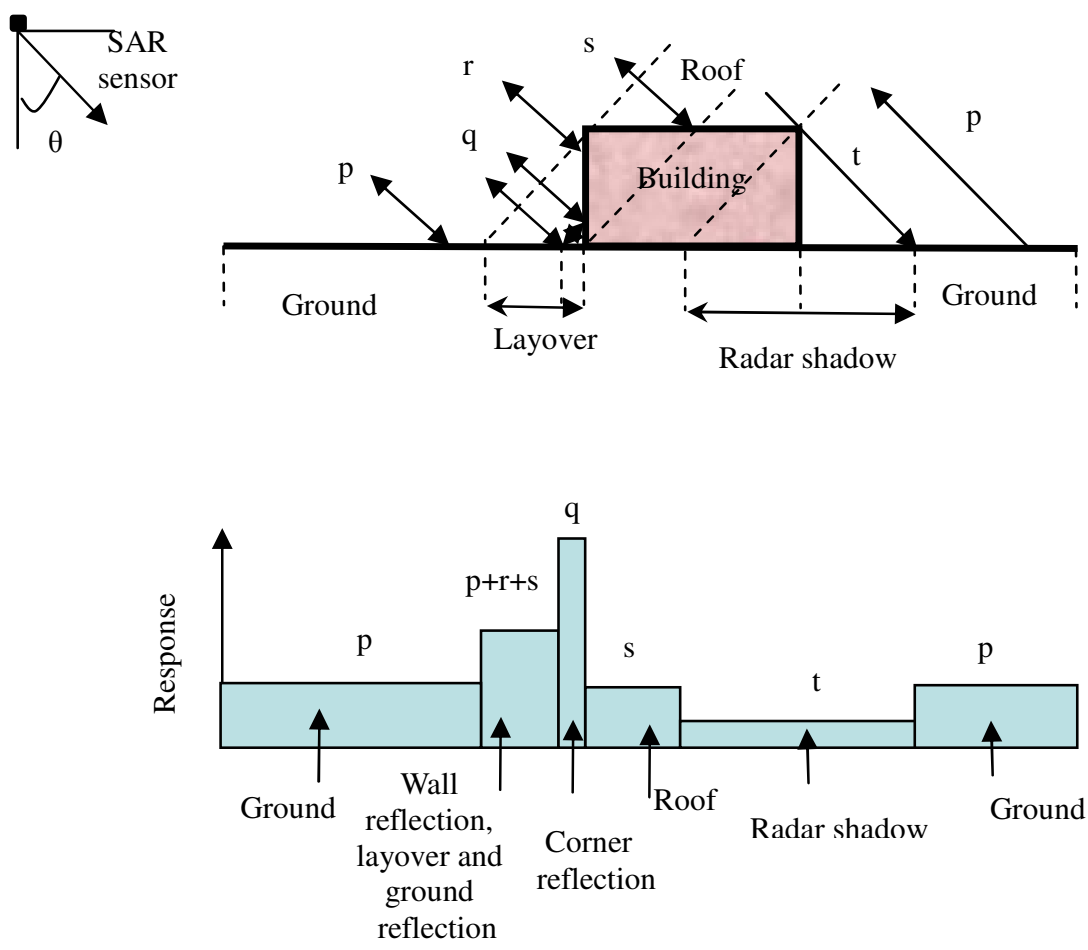

Fig. 5 Schematic diagram of ideal scattering from a typical building. Here p, q, r, s, and t are ground reflection, corner reflection, wall reflection, roof reflection and no response, respectively.

(Adapted after Brunner et al. 2010) 


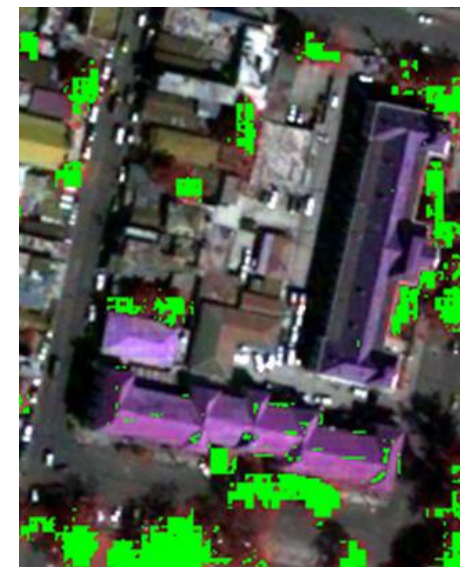

(a) 0.2

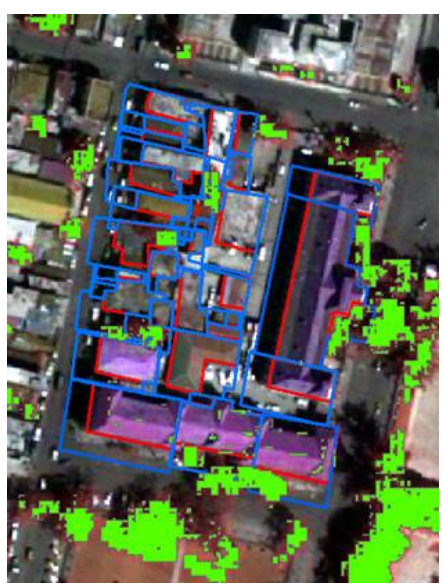

(b) 0.3

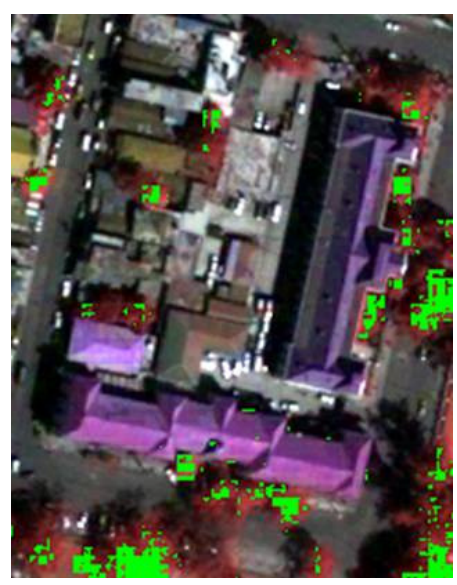

(c) 0.4

Fig. 6 Example of selection of thresholds by a trial and error method for NDVI. Different values were overlaid to the false color composite of the pre-event image. Concept of footprint extension is also shown in (b). Red polygons in (b) represent the building footprint while blue polygons are the extension of building footprint to accommodate the real situation of SAR.

\section{DAMAGE DETECTION FOR MODERATE- AND LOW-DENSITY AREAS}

One of the methods for detecting change from no change is thresholding. Thresholds can be selected generally using two methods: (a) interactive or manual trial and error procedure - in which analyst interactively adjusts the thresholds and evaluates the resulting image until satisfied; and (b) statistical measures - in which analyst selects a suitable standard deviation from a class mean (Singh 1989, Deer 1995, and Yool et al. 1997 cited by Lu et al. 2004).

NDVI from the pre-event QuickBird image was calculated in order to remove vegetated areas to avoid false extraction of building damage. For a good result, the pre-event optical image, from which NDVI is to be extracted, should be of similar time with the earthquake event. In our case the pre-event image was from February while the earthquake event was in January. When we observe the climatic condition of these two months, these months are dry season with little precipitation so there is much similarity of the vegetation condition. NDVI value depends upon the vegetation activity and differs from place to place. Miura et al. (2009) has used threshold value of 0.4 to separate the vegetated areas using a post-event image in their study for the 2006 Java earthquake. For our case, a trial and error method was used to find the proper threshold value for NDVI and comparing different thresholds that the most suitable NDVI with minimum commission error to the buildings was 0.3 . So, we chose a NDVI value of 0.3 for the separation of vegetated and non-vegetated areas.

Regarding the choice of threshold values of the correlation coefficient $(r)$ and the backscattering difference $(d)$, a trial and error method was employed to detect the damage distribution and finally the threshold values were determined. For this case we use one sample area as in Fig. 6 for getting the best threshold. We overlaid the different values of the $r$ and $d$ and looked out for values giving more precise damage detection. Regarding $r$, for Grades 4 and 5, $r=0.30$ is better while for Grades 1-3, $r=0.20$ is better. Considering the minimization of the both sides of error, we selected $r=0.25$ for the reference $r$ value. Regarding high negative backscatter, we checked with values from 3 to $5 \mathrm{~dB}$. The value $|d| \leq 3 \mathrm{~dB}$ could get the large G5 extraction, but more errors for G1 \& 2 . So $|d| \leq 4 \mathrm{~dB}$ was selected. For positive high backscatter, we also checked with values from 3 to $5 \mathrm{~dB} . d \geq 3.0 \mathrm{~dB}$ is best in this sample area but some commission errors are found in other areas. So, we decided to use $d \geq 4$ $\mathrm{dB}$. From these observations we conclude that for the given site, the minimum correlation and high backscattering difference offering a good result among different choices for the damaged building was the threshold of $r \geq 0.25$ and $|d| \geq 4 \mathrm{~dB}$ and hence these thresholds were taken for the low- and moderate density areas. An example of obtaining threshold for the backscattering difference is shown in Fig. 7. 


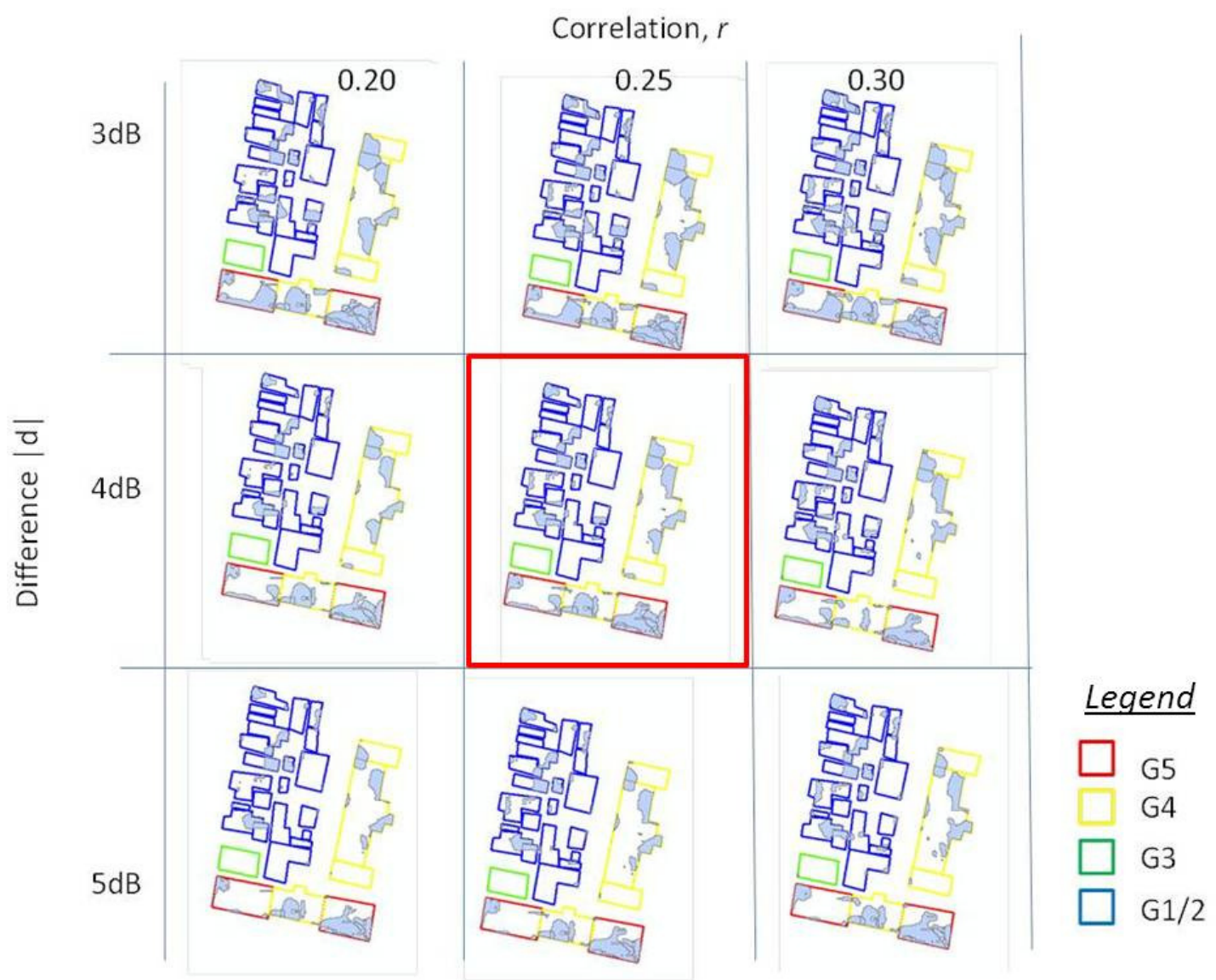

Fig.7 Example of selection of thresholds by a trial and error method for $r$ and $d$ in low- and moderate- density settings. Best threshold values obtained were either $r \geq 0.25$ or $|d| \geq 4 \mathrm{~dB}$ and this is indicated in the central figure with red square.

Regarding the accuracy of damage detection by SAR, we applied these threshold values to the study areas with low-density, moderate-density and high-density, determined from the pre-event optical satellite image. Because of the availability of the post-event optical images, they were also utilized for the classification purpose. For the low- and moderate-density areas, damages to buildings (Grades 3, 4 and 5 in the EMS-98 scale) were transferred from the post-disaster need assessment (PDNA) survey atlas to a GIS environment by drawing the building polygons over the vertical satellite images. The PDNA atlas was prepared by UNITAR/UNOSAT in collaboration with different agencies including the World Bank (UNITAR et al. 2010) for post reconstruction efforts. As UNOSAT inventory has detail of damage grades, it has been also used by other researchers (Rathje et al. 2011, Booth et al. 2011).

The threshold values for the NDVI, $r$ and $d$ were overlaid on the building footprints and the ratio was calculated to determine the percentage of areas covered by these threshold values; an area with NDVI $\leq 0.3$ and either $r \leq 0.25$ or $|d| \geq 4 \mathrm{~dB}$. By overlaying values of damaged pixels within a building footprint, we perform the individual building damage detection and subsequent damage grade classification.

Fig. 8 shows the result of the areal percentage $\left(R_{a}\right)$ by the criteria above mentioned upon the building footprints of different damage grades based on the EMS-98 scale. We used the cumulative probability distribution of $R_{a}$ of building footprints of different damage grades to determine the thresholds for the classification. The $R_{a 1}$ value, which gives the maximum vertical distance between the cumulative distribution curves for G1-2 and G3-4, and the $R_{a 2}$ value, which gives the maximum vertical distance between the cumulative distribution curves for G3-4 and G5, were chosen graphically The producer accuracy $\left(P_{A}\right)$ of different damage grades is plotted by the vertical arrows. We tried to classify the damage grades in following combinations: - (a) Grades 1-2, (b) Grades 3-4, and (c) Grade 
5, based upon the thresholds obtained from the Fig.7. So, if the ratio satisfying the threshold criteria within a building footprint is less than or equal to $25 \%\left(R_{a} \leq 25 \%\right)$ then it is considered as Grades 1-2, if $R_{a}$ is above $25 \%$ but less than $39 \%$ it is Grades 3-4 and if $R_{a}$ is more than $39 \%$ it is G5 (collapsed).

Fig. 9 shows the methodology adopted in this study.

When we took the intersection of low NDVI $(\leq 0.3)$ and backscatter characteristics $(r \leq 0.25$ or $|d|$ $\geq 4 \mathrm{~dB}$ ) for a low-density area as in Presidential Palace in Fig. 10 (up), it was found that out of 10 collapsed building footprints (Grade 5), 8 building footprints satisfy the threshold area ratio of more than $39 \%$. As discussed in methodology, they are assumed to be collapsed buildings. Similarly, 3 out of 6 buildings of damage Grades 3-4 and 6 out of Grades 1-2 could be correctly identified. It is to be noted that three G1-2 buildings were also identified as G5. Radar backscatter is affected by the path of

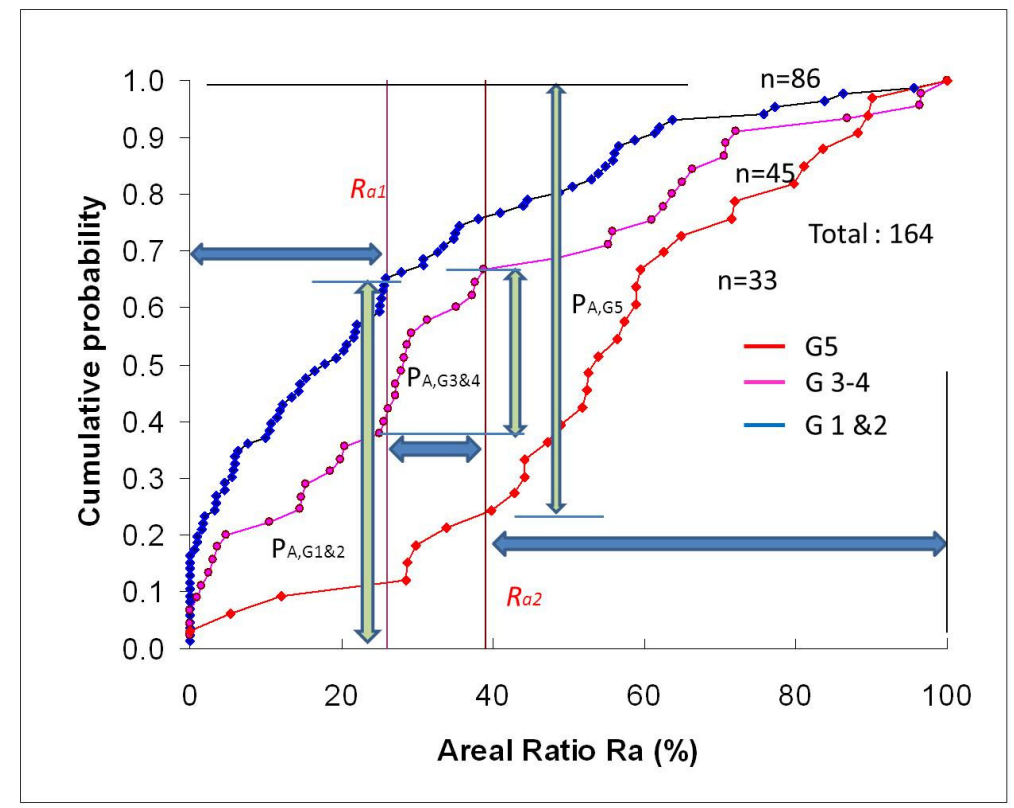

Fig. 8 Cumulative probability distribution curves showing the areal percentage satisfying the threshold values from NDVI and backscatter characteristics in a building footprint for different damage grades in moderate- and low-density settings. Here $n$ is the number of buildings in three damage classes.

TerraSAR- X

Optical images

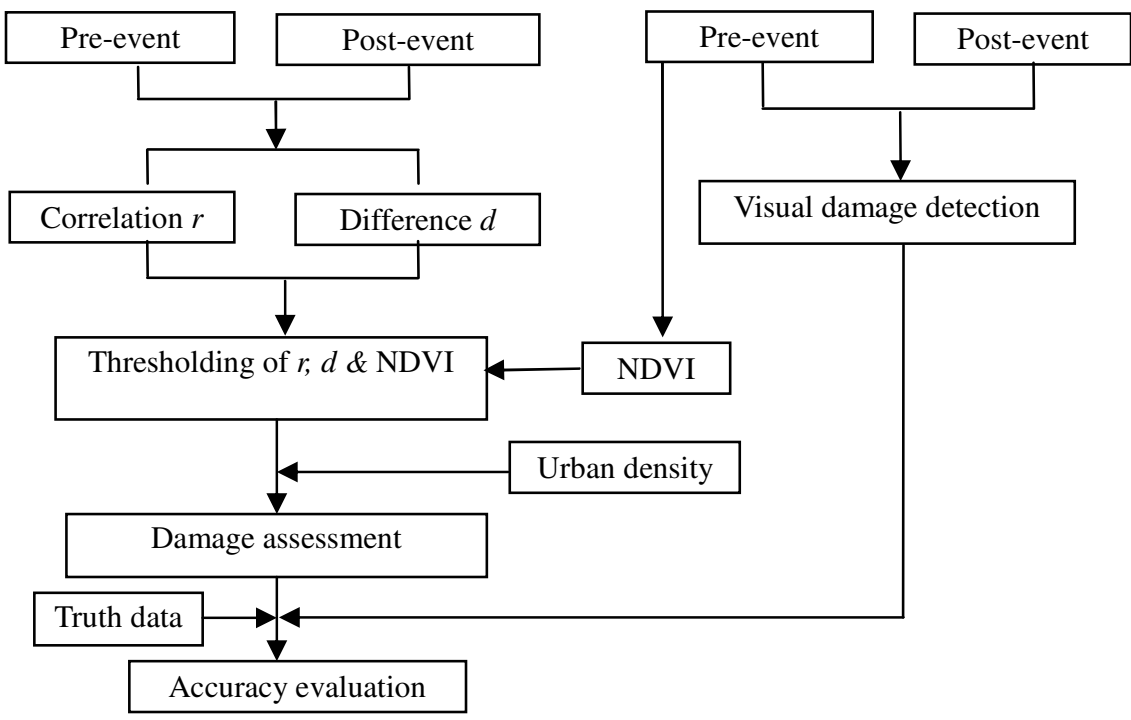

Fig. 9 Flowchart of the methodology adopted in this study. 
a satellite, a layout of buildings and even vegetation. When the orientation of a tall building is towards the radar path, the adjacent short buildings are affected by the backscatter from the tall building. This may happen to the main building in the presidential complex and the undamaged building was identified as collapsed one.

In Fig. 10 (down), there are 29 buildings. Out of two G5 building one could be identified while out of 5 Grades 3-4 buildings 3 could be found correctly. Out of 22 buildings of damage Grades 1-2, 14 were correctly identified but one was misclassified as G5 and rest 5 were misclassified as Grades 3-4. Low detection of collapsed building which were facing the ground may be due to the fact that in the urban areas, layover is common and it falls in front of buildings facing the SAR illumination. As the building polygons are drawn based on the vertical optical image, many damaged building could not be identified.

Similarly, when we took the intersection of low NDVI $(\leq 0.3)$ and backscatter characteristics $(r \leq$ 0.25 or $|d| \geq 4 \mathrm{~dB}$ ) for a moderate-density area as in Fig. 11 (up), we noticed that out of 2 collapsed buildings, 2 buildings could be correctly identified by these threshold values (the area percentage within a building footprint $\geq 39 \%$ for G 5). Out of 4 Grades 3-4 buildings 2 could be correctly recognized. Similarly out of 16 G1-2 buildings, 7 could be correctly identified but 3 and 6 buildings were misclassified as G4 and G5 respectively.

Regarding the Fig. 11 (down) there are 87 buildings out of which 19 were Grade 5, 30 were Grades 3-4 and 38 were Grades 1-2. Using our threshold values we could detect 15 out of G5 buildings. Similarly out of 38 damage Grades 1-2 buildings, 23 were correctly identified but 10 were misclassified as G5 buildings. Here many undamaged building along the road and also in the direction of SAR illumination were also detected as damaged. This may be the effects of layover and corner reflection from the road adjacent to the buildings.

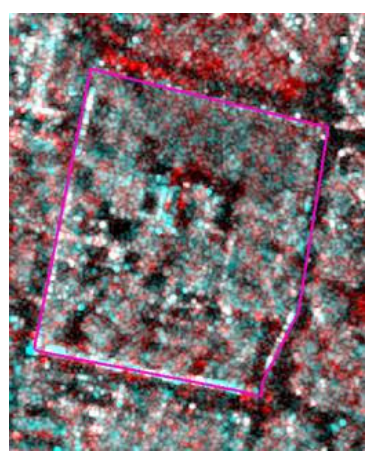

(a)

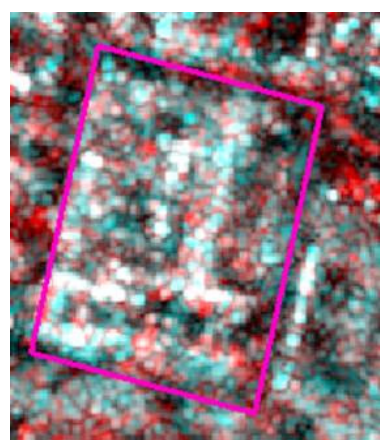

(a)

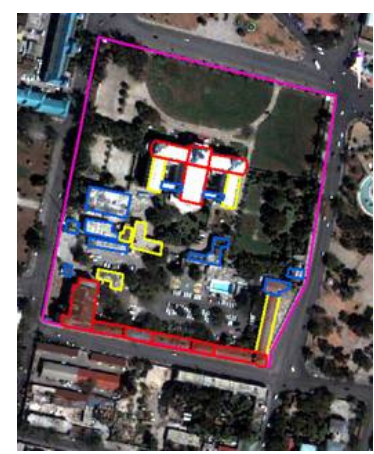

(b)

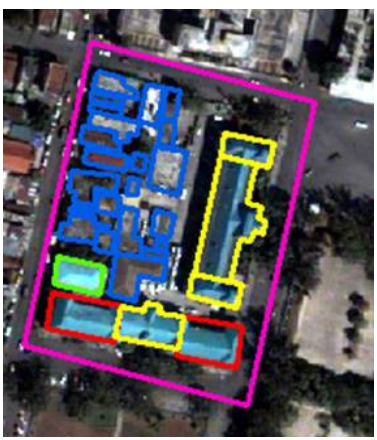

(b)

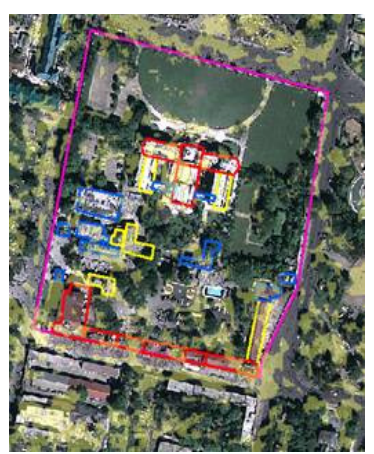

(c)

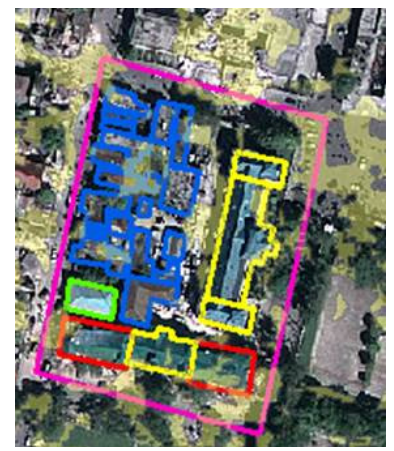

(c)

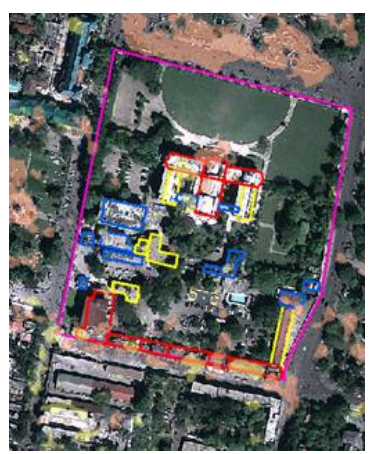

(d)

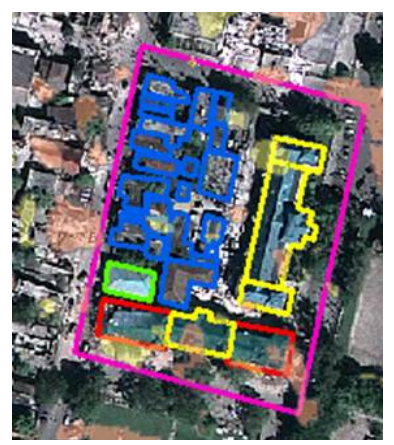

(d)

Low-density Area (ii)

Fig. 10 Examples of low-density areas (Sample areas (i) and (ii) in Fig. 4(a)). (a) Color composite (Red: post-event scene, Cyan: pre-event scene), (b) Pre-event QuickBird image, (c) Post-event GeoEye image and subsequent overlay of low correlation, $r \leq 0.25$ and low NDVI $(\leq 0.3)$, (d) Overlay of high backscatter difference $|d| \geq 4 \mathrm{~dB}$ : yellow color shows high negative $d$ while orange color shows high positive $d$. 
Table 1 shows the error matrix for the low- and moderate-density areas. Out of 33 G5 buildings, 26 buildings could be correctly identified while out of 45 G3-4 buildings it was 14. For less-damaged buildings, 50 buildings were correctly identified out of 86 G1-2 buildings. Compared to Grades 3-4, producer accuracy for G1-2 was high, suggesting that two groupings for the classification would be better. The producer accuracy for the G5 buildings was $78.8 \%$ while user accuracy was $44.1 \%$. The overall accuracy was $54.9 \%$.

If we compare the results with other studies regarding the accuracy, Matsuoka and Yamazaki (2004) used the linear discriminate analysis in damage detection for the 1995 Kobe, Japan earthquake. They achieved $78 \%$ overall accuracy. Likewise, Gamba et al. (2007) used SAR image (30m resolution) for the $2003 \mathrm{Bam}$, Iran earthquake and obtained the producer accuracy ranging from 65 to 75\%. Similarly, Giovanna and Gamba (2009) used the damage detection in the 1999 Golcuk, Turkey earthquake using ERS-1 and ERS-2 SAR images and were able to obtain overall accuracy ranging from 53.5 to $60.6 \%$. All these damage detection methods were used for the block level not in an individual building level. So, we cannot directly compare our results with them because of the different data type, urban context as well as different approach of damage detection. However, our result is considered to be in an acceptable level.

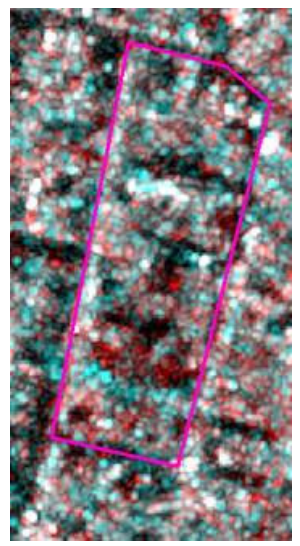

(a)

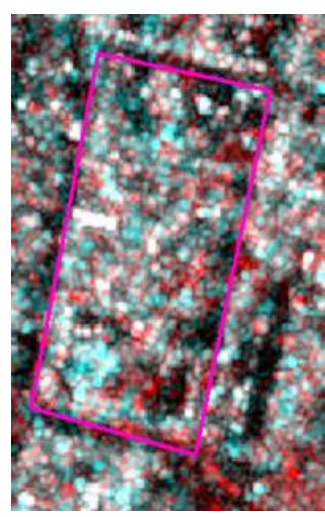

(a)

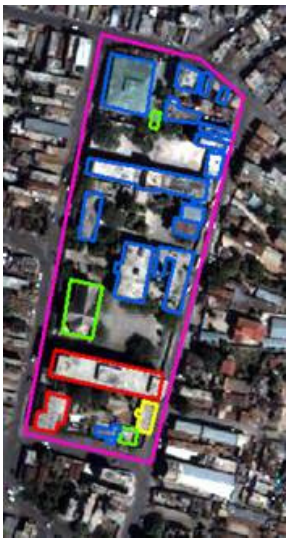

(b)

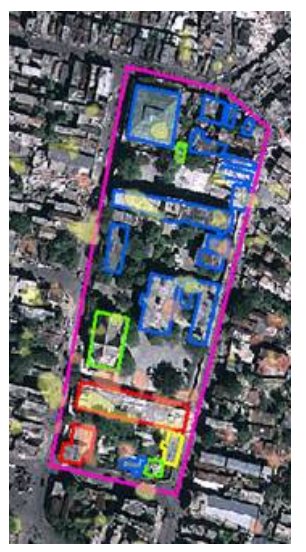

(c)

Moderate-density Area (iv)

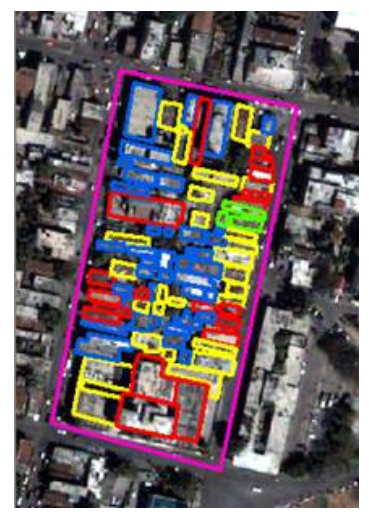

(b)

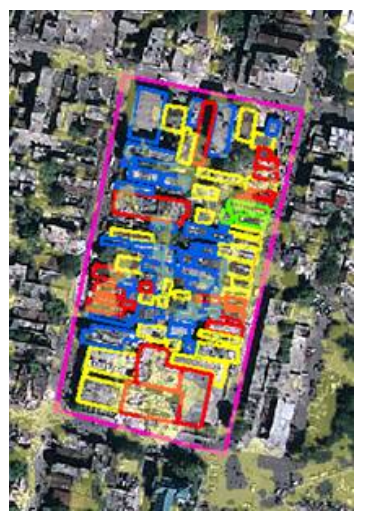

(c)

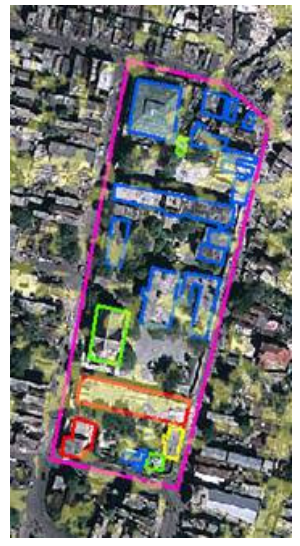

(d)

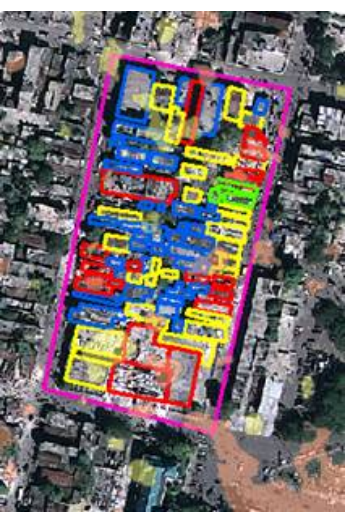

(d)

Moderate-density Area (iii)

Fig. 11 Examples of moderate-density areas (sample areas (iii) and (iv) in Fig. 4(a)). (a) Color composite (Red: post-event scene, Cyan: pre-event scene), (b) Pre-event QuickBird image, (c) Post-event GeoEye image and subsequent overlay of low correlation, $r \leq 0.25$ and low NDVI $(\leq 0.3)$, (d) Overlay of high backscatter difference $|d| \geq 4 \mathrm{~dB}$ : yellow color shows high negative $d$ while orange color is high positive $d$. 
Table 1 Error matrix for low- and moderate-density areas

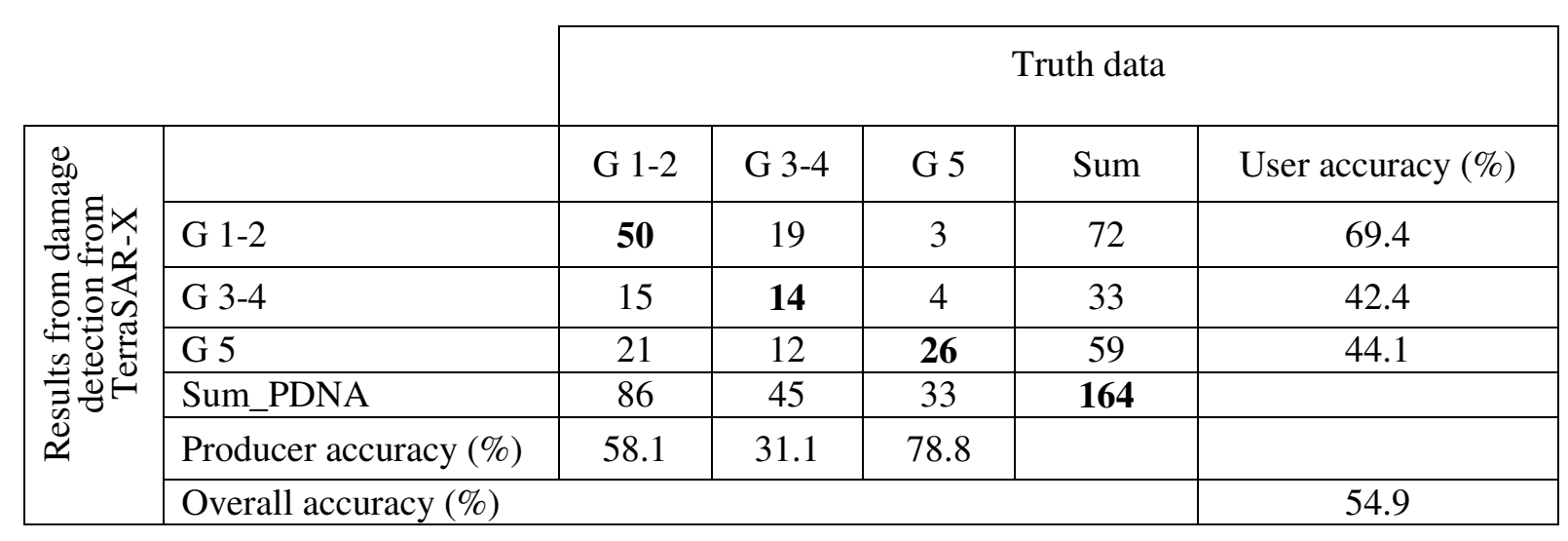

\section{DAMAGE DETECTION FOR HIGH-DENSITY AREAS}

Regarding the high-density area, area-based damage estimation was carried out as it was difficult to extract the building footprint. Vegetation was removed by the threshold NDVI value of 0.2 because in this case, we must remove vegetation within a block and we found that this value is most suitable for that objective.

Figs. 12 and 13 show two sample high-density blocks where we have used the area-based damage estimation. For this purpose the threshold value was first evaluated in the sample area (vi). We compared the different threshold values of $r$ and $d$. We noticed that backscatter difference was not significant compared to the correlation in detecting damaged buildings. This may be due to the fact that when buildings are very near to each other, backscatter contribution from the wall (corner reflection) is less and roof is mainly contributing to the backscatter returns to radar hence there is low backscatter even in the normal condition. After the disaster, damaged buildings will have less backscatter and this was more clearly seen from the correlation thresholds than the backscatter difference. So, we only used the threshold value of correlation.

We did visual damage detection of the buildings using the temporal optical images as well as took the reference of the PDNA map in the high-density sample areas. The damaged building points (Grades 3-5) were then superposed on the different threshold values of $r$ in a GIS environment. The area with highest incorporation of damaged buildings was selected for the threshold and we get the best result with $r \leq 0.10$. Hence $r \leq 0.10$ was determined as the threshold and it was also used for the evaluation in the next sample area. We calculated the total area covered by low correlation, the area of vegetation, and the net block area (the block area - the vegetated area). The area extracted by the threshold $(r \leq 0.10)$ was divided by the net block area to evaluate the probable damage ratio.

The area covered by the threshold values in these two sampled blocks is $19,510 \mathrm{~m}^{2}$ while the net block areas is $147,426 \mathrm{~m}^{2}$. So, the possible damage area corresponds to about $13.2 \%$ of the total. The reason of the low detection ratio from the SAR images might be explained by the density of the study area. It is to be mentioned that although we used the PDNA's result as the truth data, it was produced from the visual inspection of satellite and vertical aerial images. But there is limitation of damage detection from vertical images as damages to side of buildings cannot be observed. Use of oblique photography like pictometry (Saito et al. 2010) may be more useful than the vertical optical images in comparing results of building damage detection from SAR. Survey data from the ground is, of course, more accurate and essential for detailed assessment. 


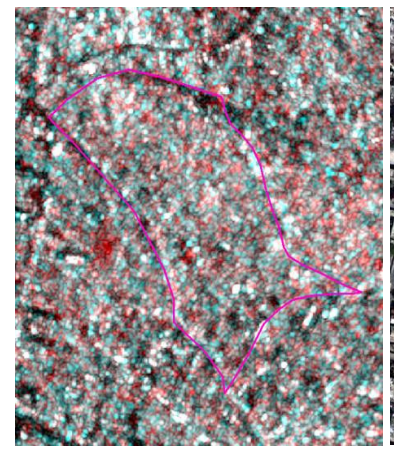

(a)

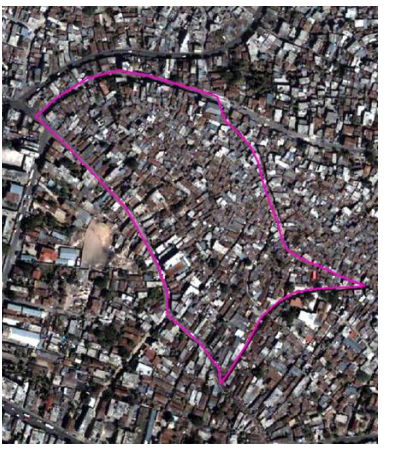

(b)

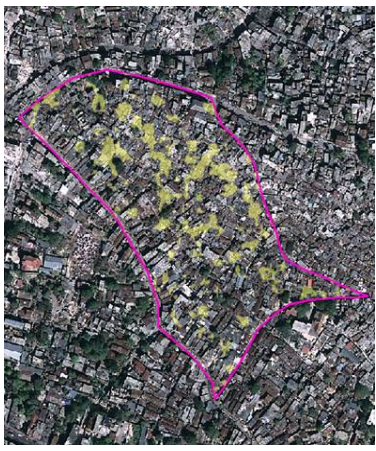

(c)

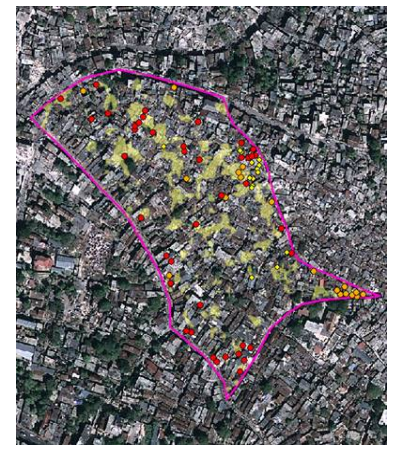

(d)

High-density Area (vi)

Fig. 12 Example of extraction of threshold for high-density area (sample areas (vi) in Fig. 4(a)).

(a) Color composite (Red: post-event scene, Cyan: pre-event scene), (b) Pre-event QuickBird image, (c) Post-event GeoEye image and subsequent overlay of low correlation, $r \leq 0.10$ and low NDVI ( $\leq 0.2)$ (d) Overlay of damage grade points (Red: G 5, Orange: G 4 and Yellow: G 3) on the best threshold.

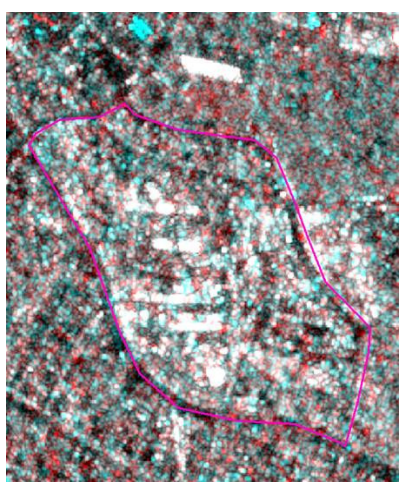

(a)

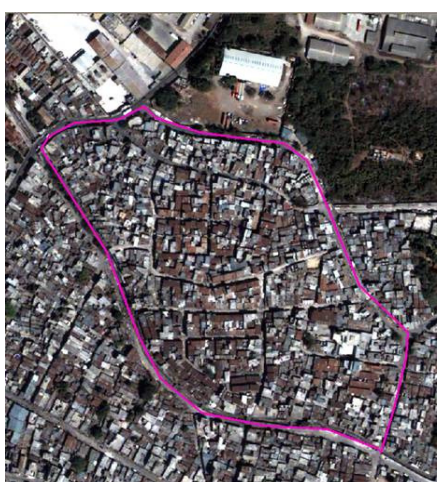

(b)

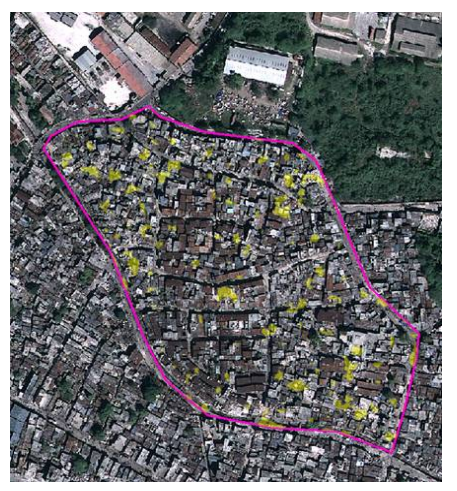

(c)

High-density Area (v)

Fig. 13 Example of application of backscatter threshold for high-density area (sample areas (v) in Fig. 4(a)). (a) Color composite (Red: post-event scene, Cyan: pre-event scene), (b) Pre-event QuickBird image (c) Post-event GeoEye image and subsequent overlay of low correlation, $r \leq 0.10$ and low NDVI $(\leq 0.2)$.

\section{CONCLUSIONS}

High-resolution SAR intensity images from TerraSAR-X were used in detecting the building damages for the 2010 Haiti Earthquake. Building damage detection considering side-looking nature of SAR was introduced and used in the extension of building polygons to the direction of SAR illumination. Because of the contamination by vegetation in the extended part, it could not be used in our case. This extension concept might be more effective in building damage detection in the places where there is little effect of vegetation to buildings. We calculated the correlation coefficient and the backscatter difference from the pre- and post-event intensity images and the threshold values from them were evaluated into three different building density areas: low-, moderate- and high-density.

We could detect damaged buildings at an individual building level in three groups: damage Grades 1 and 2, damage Grades 3 and 4 and damage Grade 5 in the low-, and moderate-density areas with low correlation and large backscattering differences. Detection of collapsed buildings (Grade 5) could be done with producer accuracy of $78.8 \%$ and user accuracy of $44.1 \%$ and overall accuracy of all groups was $54.9 \%$. 
Area-based damage detection was introduced for high-density areas because building footprints were difficult to construct there. The accuracy of damage detection was not so high to these areas. To assess to accuracy of the damage detection from SAR intensity images, however, more reliable ground truth data are necessary.

\section{ACKNOWLEDGMENT}

The TerraSAR-X images used in this study were made available from SAR Application Research Committee, organized by PASCO Corporation, Tokyo, Japan.

\section{REFERENCES}

Booth, E., Saito, K., Spence, R., Madabhushi, G., and Eguchi, R.T. (2011). "Validating Assessments of Seismic Damage Made from Remote Sensing." Earthquake Spectra, Vol.21 (SI), pp. S157-S177

Breit, H., Fritz, T., Balss, U., Lachaise, M., Niedermeier, A., and Vonavka, M. (2010). "TerraSAR-X SAR Processing and Product." IEEE Transaction on Geoscience and Remote Sensing, 48 (2), 727-740.

Brunner, D., Lemoine, G., and Bruzzone, L. (2010). "Earthquake Damage Assessment of Buildings Using VHR Optical and SAR Imagery." IEEE Transaction on Geoscience and Remote Sensing, 48 (5) 2403-2420.

Brown, L.G. (1992). "A Survey of Image Registration Techniques." ACM Computing Surveys, 24 (4).

Cambell J.B. (2002). Introduction to Remote Sensing. $3^{\text {rd }}$ edition, Guilford, USA.

Cambridge Architectural Research Ltd (2010). "Port-au-Prince Earthquake Damage Assessment Using Pictometry."

http://www.eqclearinghouse.org/20100112-haiti/wp-content/uploads/2010/02/PaP_damage-assessm ent-using-Pictometry.pdf

Cavallo, E.A., Powell, A., and Becerra, O. (2010). "Estimating the Direct Economic Damage of the Earthquake in Haiti." IDB Working Paper Series No.IBD-WP-163, Inter American Development Bank, USA.

Dell'Acqua, F., Trianni, G., Gamba, P., and Houshmand, B. (2006), "Statistical Analysis of SAR Data to Improve Damage Mapping at Block Scale." 4th International Workshop on Remote Sensing for disaster management, Cambridge.

Eberhard, M.O., Baldridge, Steven, Marshall, Justin, Mooney, Walter, and Rix, G.J. (2010), "The MW 7.0 Haiti Earthquake of January 12, 2010; USGS/EERI Advance Reconnaissance Team report: U.S. Geological Survey Open-File Report 2010-1048." 58.

Gamba, P., Dell'Acqua, F. and Trianni, G. (2007) "Rapid Damage Detection in Bam Area Using Multitemporal SAR and Exploiting Ancillary Data." IEEE Transaction of Geosicence and Remote Sensing, 45(6), 1582-1589.

Government of Haiti. (2010). "Action Plan for National Recovery and Development of Haiti."

Huang, X., and Kwoh, L.K. (2007). "3D building Reconstruction and Visualization for Single High Resolution Satellite Image." Proceedings of the IEEE 2007 International Geoscience and Remote Sensing Symposium, pp. 5009-5012.

Huyck, C.K., Mansouri, B., Eguchi, R.T., Houshmand, B., Castner, L.L., and Shinozuka, M. (2002). "Earthquake Damage Detection Algorithm Using Optical and ERS-SAR Satellite Data Application to the August 17, 1999 Turkey Earthquake." Proceeding of the 7th National US Conference on Earthquake Engineering, Boston.

Infoterra (2008). "Radiometric Calibration of TerraSAR-X data."

Iwasaki, Y., and Yamazaki, F. (2011). "Detection of Building Collapse from the Shadow Lengths in Optical Satellite images." Proc. 32nd Asian Conference on Remote Sensing, Taipei, Paper No. 202, CD-ROM, 6p.

Lilles, T., and Kiefe, R. (2000), Remote Sensing and Image Interpretation, John Wiley and Sons, Inc, USA. 
Lu, D., Mausel, P., Brondizio, E., and Moran, E. (2004). "Change Detection Techniques." International Journal of Remote Sensing, 25 (12), 2365-2407.

Lee, J. S. (1980). "Digital Image Enhancement and Noise Filtering by Use of Local Statistics." IEEE Transaction, Pattern Analysis and Machine Intelligence, Photographic Surveying and Remote Sensing, Vol.2, No.2, 165-168.

Matsuoka, M., and Nojima, N. (2010). "Building Damage Estimation by Integration of Seismic Intensity Information and Satellite L-band SAR Imagery." Remote Sensing, 2, 2111-2126 doi:10.3390/rs2092111.

Matsuoka, M., and Yamazaki, F. (2004). "Use of Satellite SAR Intensity Imagery for Detecting Building Areas Damaged due to Earthquakes.” Earthquake Spectra, 20 (3), 975-994.

Matsuoka, M., and Yamazaki, F. (2005). "Building Damage Mapping of the 2003 Bam, Iran Earthquake using Envisat/ASAR Intensity Images." Earthquake Spectra, Vol.21 (S1) pp S285-S294

Matsuoka, M., and Yamazaki, F. (2010). "Comparative Analysis for Detecting Areas with Building Damage from Several Destructive Earthquakes using Satellite Synthetic Aperture Radar Images." Journal of Applied Remote Sensing, SPIE, 4 (1), 1-16.

Olson, S. M., Green, R. A., Lasley, S., Martin, N., Cox, B.R , Rathje, E M., Bachhuber, B., and French, J. (2011). "Documenting Liquefaction and Lateral Spreading Triggered by the 12 January 2010 Haiti Earthquake." Earthquake Spectra, Vol.27 (SI) pp. S93-S116.

Rathje, E., and Adams, B. (2008). "The Role of Remote Sensing in Earthquake Science and Engineering: Opportunities and Challenges." Earthquake Spectra 24 (2), 471-492.

Rathje, E M., Bachhuber, J., Dulberg R., Cox, B.R., Kottke, A., W, Clinton., Green, R. A., Olson, S., Wells D., and Rix, G. (2011). "Damage Patterns in Port-au-Prince during the 2010 Haiti Earthquake." Earthquake Spectra, Vol.27 (SI) pp. S117-S136.

Republic of Haiti. (2003). Plan-Programme de Développement de la Zonemétropolitaine de Port-au-Prince.

Stramondo, S., Bignami, C., Chini, M., Pierdicca, N., and Tertulliani, A. (2006). "Satellite Radar and Optical Remote Sensing for Earthquake Damage Detection: Results for Different Case Studies." International Journal of Remote Sensing, 27 (20), 4433-4447.

Sabins, F.F. (1996). Remote Sensing: Principles and Interpretation (3) Freeman, New York.

Saito, K., Spence, R., Going, C. and Markus, M. (2004). "Using High-Resolution Satellite Images for Post-Earthquake Building Damage Assessment: A Study Following the 26 January 2001 Gujarat Earthquake." Earthquake Spectra 20, 145-169.

Saito, K., Spence. R., Booth, E., Madabhushi, G., Eguchi, R., and Gill, S. (2010). "Damage Assessment of Port au Prince using Pictometry." ${ }^{\text {th }}$ International Conference on Remote Sensing for Disaster Response, Tokyo, Japan.

Thao, N.V., Lan, D. T., Huong D.T., and Ve, N.D. (2010). “Assessing Damage of Flood by Using ALOS Data in Thua Thien-Hue Province." The 4th Joint PI symposium of ALOS Data nodes for ALOS Science Program, Tokyo, Japan, 125.

UNDP, (2010). http://www.ht.undp.org/_assets/fichier/publication/brochures_debris_en.pdf.

United Nations Human Settlements Programme (UN-HABITAT) (2009). "Strategic Citywide Spatial Planning: A Situational Analysis of Metropolitan Port-au-Prince, Haiti.";

United Nations Institute for Training and Research (UNITAR), Operational Satellite Applications Programme (UNOSAT) European Commission (EC), Joint Research Centre (JRC) and The World Bank. (2010). "Atlas of Building Damage Assessment Haiti Earthquake 12 January 2010 in Support to Post Disaster Needs Assessment and Recovery Framework (PDNA)."

United States Geological Survey (2010). http://earthquake.usgs.gov/ 